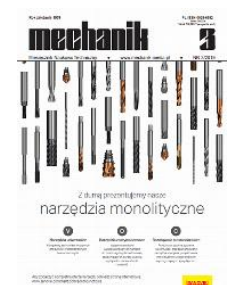

How to cite this article:

Author: Wit Grzesik

Title of article: „Application of process signature concept to prediction of the functional properties of machine parts”

Mechanik, No. 3 (2019)

DOI: https://doi.org/10.17814/mechanik.2019.3.25

\title{
Application of process signature concept to prediction of the functional properties of machine parts
}

\section{WIT GRZESIK *}

* $\quad$ Prof. DSc PhD Eng. Wit Grzesik, w.grzesik@po.opole.pl, https://orcid.org/0000-0003-3898-5119 - Department of Manufacturing Technology and Production Automation, Faculty of Mechanical Engineering, Opole University of Technology (Politechnika Opolska), Opole, Polska

The purpose of this survey is to explain and determine the relationships between physical state of the machining process, i.e. the decisive physical phenomena occurring during the process and the functional properties of the machined parts using the concept of process signatures. Dominant phenomena and energy transformation in the machining process are quantified in terms of the functionality of the technological subsurface layer. Some practical examples of the application of process signature to the producing of subsurface layer with demanded functional properties are presented and discussed. KEYWORDS: machining processes, process signature, surface layer, functional properties

In previous author's publications in Mechanik [1, 2], practical possibilities to improve the technological and exploitational quality of functionally important parts by means of finishing machining and hybrid operations were repeatedly discussed. These considerations were based on measured parameters of 2D and 3D surface roughness, which have significant influence on functional properties. The role of technological surface layer (TSL), which includes not only the real surface, but also the subsurface layer with physical (mechanical) and chemical properties changed due to various energy interactions, was omitted in them [3, 4]. Engineering knowledge in this area is still insufficient, although the techniques for measuring and simulating surfaces, stresses, hardness and microstructure are still being improved. In engineering design, not only dimensional tolerances and shape accuracy are important, but also the relationships between TSL functionality and its geometric and physical state. In engineering practice, TSL state relationships are related to many important functional properties, such as fatigue strength, wear and corrosion resistance, as well as contact pressure (contact strength) $[1,3]$.

It should be mentioned that the term 'surface layer' was introduced to Polish scientific and technical literature by J. Kaczmarek [4], based on earlier CIRP works from 1964 [5].

The current state of research of manufacturing/machining processes is so developed that it can be initially predicted how the surface layer of a workpiece will behave in mating and how it will fulfill its desired functions during exploitation [6, 7]. The guiding principle is the integration of geometrical and physical features of the surface layer with the behavior of parts during operation, which, according to Polish technical terminology, is referred to as 'technological and exploitational quality' [8]. The issue of the production and use of surface layers has been described in quite detail by T. Burakowski in a monograph [9] devoted to aerology, i.e. a branch of science and technology equivalent to surface engineering.

Difficulties encountered by manufacturing engineering when attempting to combine technological and exploitational quality are still too great to be able to predict individual functional properties on the basis of measured surface roughness parameters, strengthening of the subsurface layer, introduced residual stresses and induced changes in microstructure. This position is confirmed by the results of comparative tests (Round Robin type) conducted as part of the CIRP working group "Surface Integrity and Functional Performance of Components" by nine leading research centers in the world for the three types of correlations shown in fig. $1 a$. There were considerable scatters of measurements of the parameter $R a$ of surface roughness, hardness and residual stress (up to $300 \%$ for titanium alloy Ti6Al4V after calibration of FEM models) for various 
construction materials and machining methods (fig. $1 \mathrm{~b}$ ). There is also a lack of satisfactory agreement of the results of analytical modeling and numerical simulation by the FEM method. Usually, the results of metallographic measurements and analyses are verified in tests carried out on specialized devices, e.g. fatigue machines, tribometers or devices (in chambers) for corrosion resistance tests according to the procedures specified in relevant standards.

a)

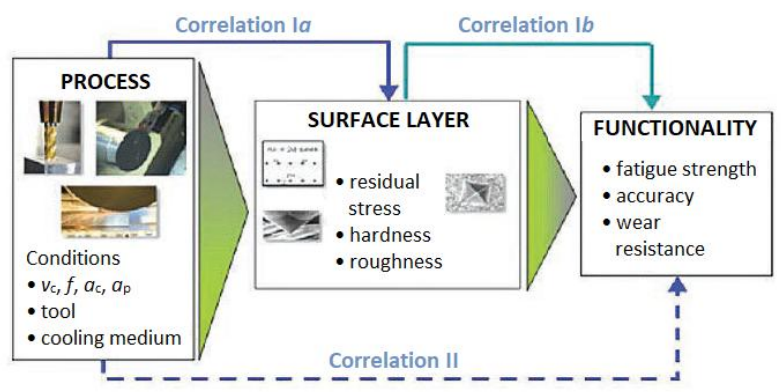

b)

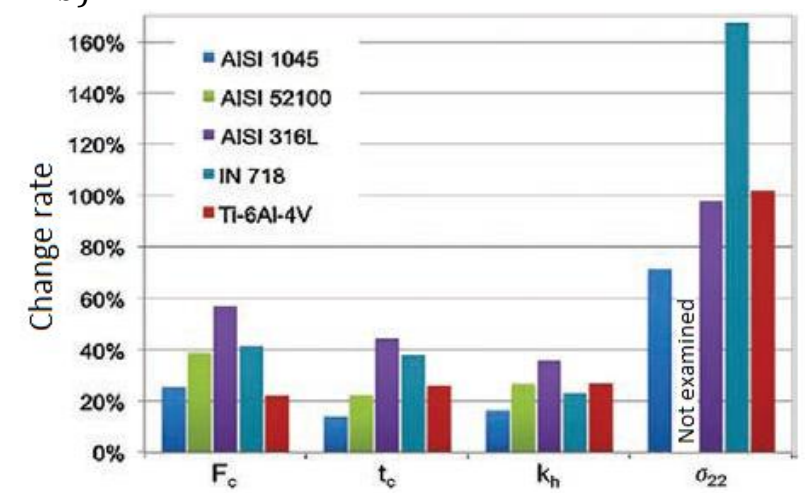

Fig. 1. Possible correlations assessed in Round Robin test $(a)$ and variations of measurement results for various process characteristics $(b)$ [6]. Designations: $F_{\mathrm{c}}$ - cutting force, $t_{\mathrm{c}}$ - cutting temperature, $k_{\mathrm{h}}$ - chip compression ratio, $\sigma_{22}-$ axial internal stress

The classic approach to TSL testing (fig. 2) uses the relationships between the state of technological surface layer and input factors that define the process conditions, and its impact on the behavior of parts in exploitation (exploitational properties). These relationships are marked in fig. 1 as type I $a$ and I $b$ correlations, considered in studies carried out as part of the CIRP working group initiative [6]. In general, they can be considered as system structures in the structural model of machining, created in a specific hierarchy of goals [3]. Especially the separation of functional factors in the structural model leads to a quantitative description of the physical mechanism of the cutting process and its impact on the state of the surface layer and functional properties.

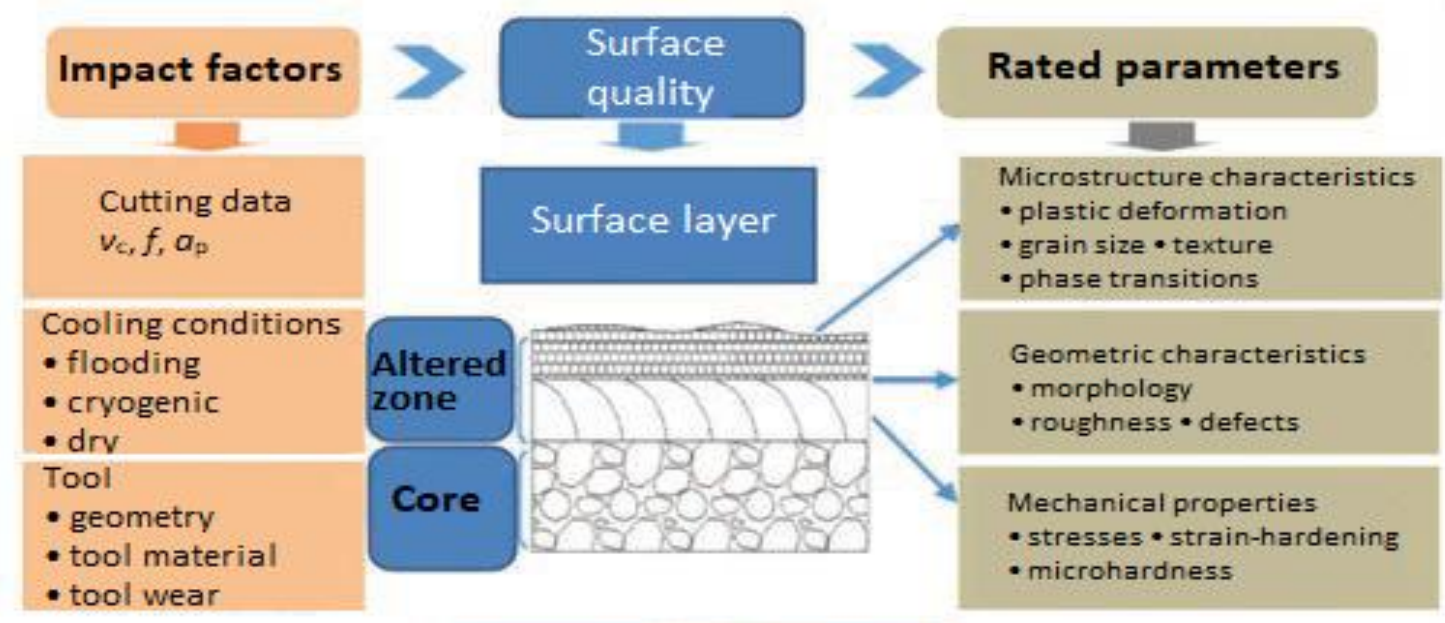

Impact

Functional surface properties

Fig. 2. Relationships between surface quality, relevant process factors and TSL characteristics [10]

A similar approach to the structural model, named in the original process signature (PS), was proposed in [11-17]. The process signature should be interpreted as a set of functional characteristics present in the physical model of the process [3]. Its essence is to identify basic mechanisms of the process (mechanical, thermal and chemical as well as their combinations) that result in irreversible changes in the properties of the 
processed material during the process. According to the originators, this approach will become the nucleus of designing the knowledge-based manufacturing processes for specific assumptions about the functionality of machine parts. According to fig. $3 a$, the process is defined by such input factors as characteristics of the material being processed and the tool used as well as machining conditions. Depending on the type of interaction between the elements of the machining system, the following are separated:

- external mechanical and thermal loads exerted on the material,

- internal mechanical and thermal loads (e.g. deformation and temperature fields) arising in the material during the process.

a)

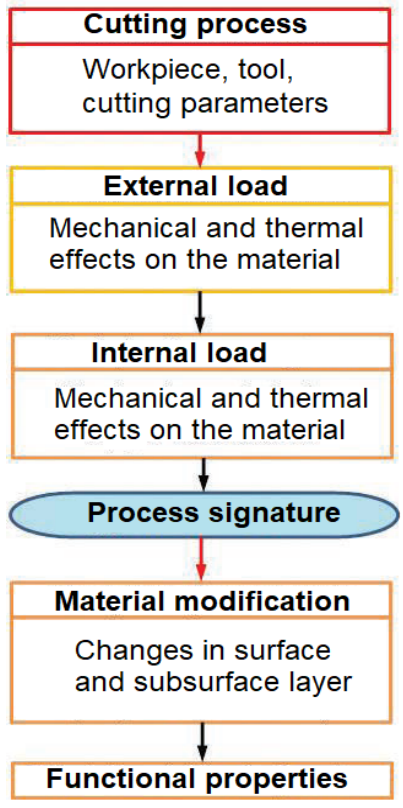

b)

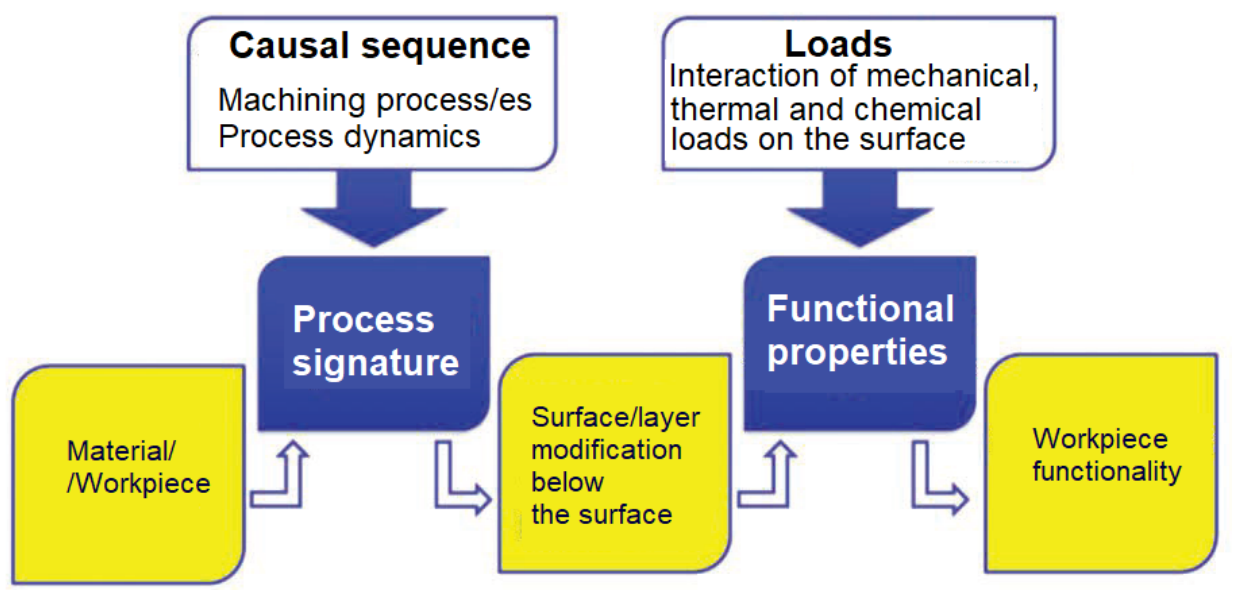

Fig. 3. Schema of the process signature type approach in predicting the exploitational properties of machined parts $(a)$ and the interrelationship of occurring interactions $(b)$ [11-13]

External and internal loads are represented by respective energy fluxes $E_{\text {mech }}, E_{\text {term }}$ and $E_{\text {chem }}$ (fig. $4 a$ ). As a result, the initial state of the material changes (modifications), and the sum of modifications determines the final geometric and physical state of the surface layer, i.e. surface integrity [3]. After defining the functional effects of the process, the reverse task is solved $[11,12,15]$, i.e. for a defined set of required surface topographies and properties of the subsurface, the conditions for the process of manufacturing parts with the required functional properties (required functionality) are established.

a)

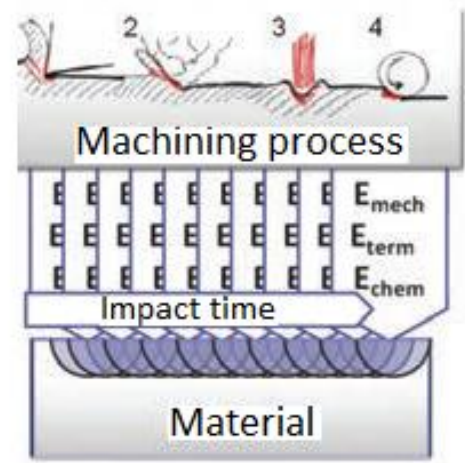

b)

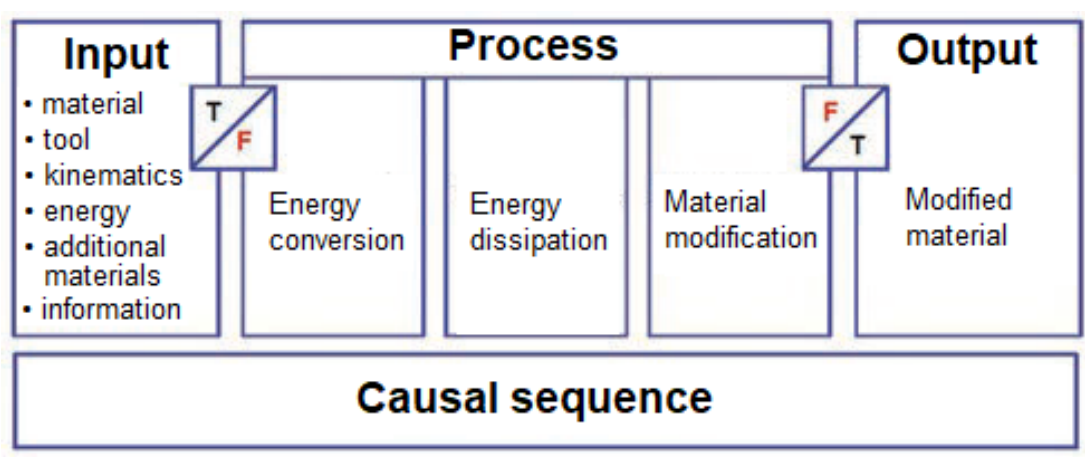

Fig. 4. Overview diagram of controlling functional interactions in various machining methods (at different internal loads): 1 - cutting; 2 - abrasive machining;

3 - machining with concentrated beams of photons, ions, atoms; 4 - burnishing $(a)$ and defining the structure of the physical model and causal sequence $(b)$ [12] 
a)

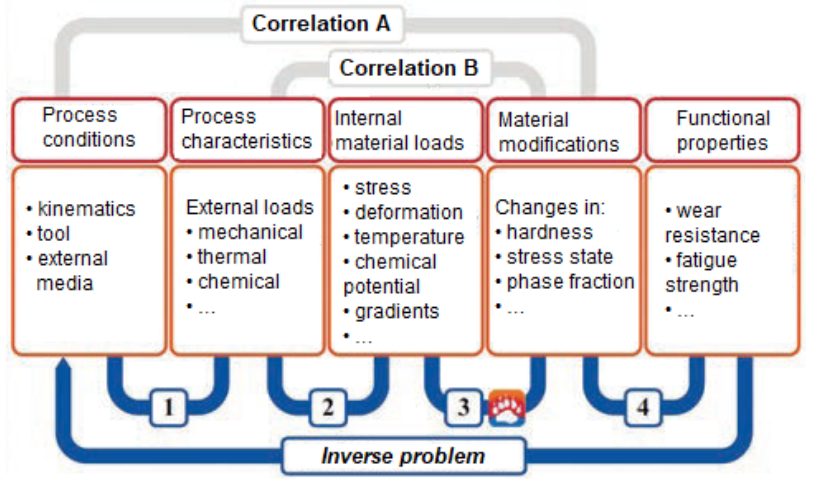

b)

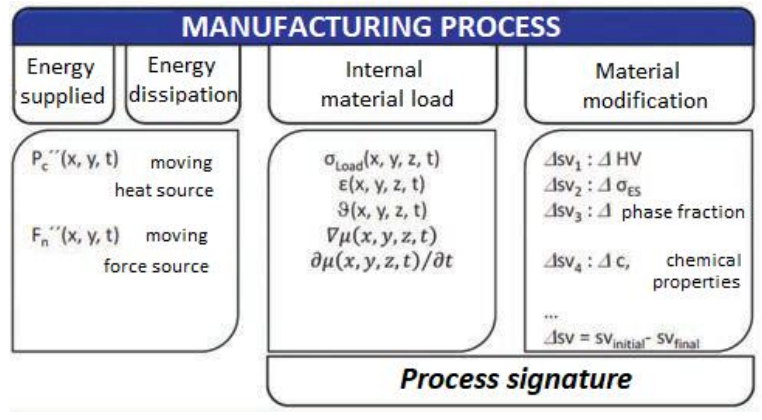

Fig. 5. Causal sequences occurring in the manufacturing processes $(a)$ and examples of defining the causes sequences and process signature components $(b)[13,14]$

The separate process signatures are intended to characterize - in a unified manner - peculiar features of various manufacturing processes and their interactions in the workpiece. This is possible when the process description usually by means of parameters or productivity indicator will be successfully replaced by fundamental physical and chemical dependencies, which in turn will be modeled on a different scale to obtain a general description in the form of process signatures. Therefore, the material is an integral part of the new process description, which is indicated in fig. $4 a$. It should be added that the time of process (load) duration on the material determines at the same time the time, at which energy conversion and dissipation occur. This may, e.g. apply to heat flow considering the volume and time gradient. Assuming that the production processes are generally based on energy conversion and dissipation, the cutting process in physical terms is implemented - to a greater or lesser simplification - according to the scheme shown in fig. $4 b$. As a result, the sequence of causes resulting in controlled modifications of material properties is determined (also marked in fig. $3 b$ ). By analogy with A/D converters, technological-physical (T/F) and physical-technological (F/T) converters were introduced.

In relation to industrial practice, it is important to examine the influence of process conditions (currently intensive research is carried out on the grinding process) on the resultant material modifications, which is represented by correlation A in fig. $5 a$. It can be an analysis of the impact of the tool material on the stress distribution profile during hard milling of gears [13]. The subsequent step towards a generalized description of the material state modification is the B correlation, as a result of replacing the process conditions by physical characteristics of the process, e.g. cutting force components or cutting power. It gives good results when such internal load characteristics as stresses, deformations, temperature or their respective change gradients are introduced. This leads to type 2 and 3 correlations, which are the missing link to the inverse solution, i.e. the relationship of functional properties with the conditions of the machining process. Fig. $5 b$ lists some component process signature (CPS), such as deformations $(\varepsilon)$, temperature field gradients - del operator $(\nabla \vartheta)$, dislocation density $(\Delta \rho)$, chemical properties ( $\Delta$ phases - change of phase fraction, $c$ - phase fraction, $\partial \mu / \partial t$ - change in chemical potential), which are responsible for the change in the state of the material $[18,19]$. It is worth noting that the components of the process signature should be determined at the macro- and microstructure level, e.g. $1^{\text {st }}$ and $2^{\text {nd }}$ type internal stress, which, however, are closely related.

\section{Examples of practical application of the process signature concept}

Basic premise that must be kept in mind when developing and analyzing the process signature concept is that each manufacturing process is characterized by the appropriate combination of material loads. This means that the final state of the surface and subsurface layer depends on the individual mechanical, thermal and chemical loads or their combinations. Processes, in which one main influence dominates, are: deep rolling - mechanical effect, EDM - thermal effect and ECM - chemical effect. Popular processes, e.g. grinding or machining, are examples of combined mechanical and thermal interactions. Fig. 6 shows classification of internal loads for various manufacturing processes, taking into account two criteria given previously. The research conducted so far $[12,13]$ shows that a certain group of manufacturing processes (fig. 7) has similar potential when it comes to the generation of the required TSL properties. 


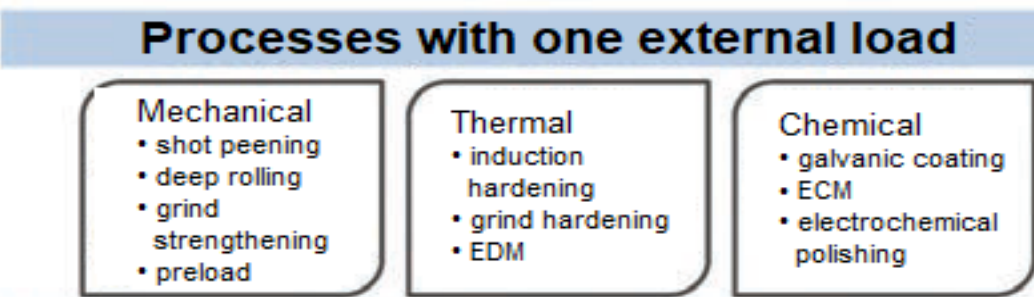

\section{Processes with a complex external load}

\begin{tabular}{|c|c|}
\hline $\begin{array}{l}\text { Thermal } \\
\& \text { Mechanical } \\
\text { - machining } \\
\text { - grinding } \\
\text { - friction welding }\end{array}$ & $\begin{array}{l}\text { Thermo-chemical } \\
\text { - carburizing } \\
\text { - laser etching } \\
\text { - sintering } \\
\text { - coating }\end{array}$ \\
\hline & $\begin{array}{l}\text { Mechanical-thermo- } \\
\text {-chemical } \\
\text { - massive abrasive } \\
\text { polishing }\end{array}$ \\
\hline
\end{tabular}

Fig. 6. Specification of loads occurring in manufacturing processes [13]

\section{THERMAL/THERMO-MECHANICAL}

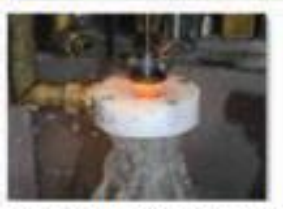

Induction hardening

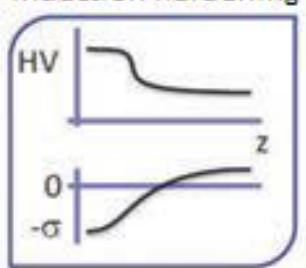

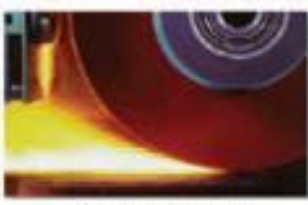

Grind hardening

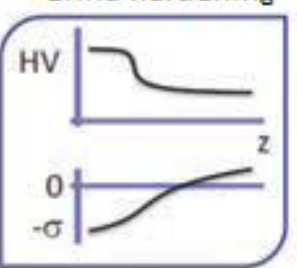

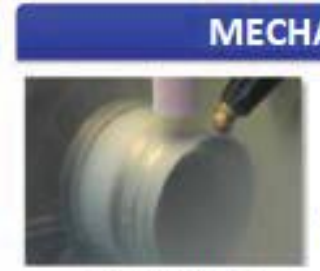

Deep rolling

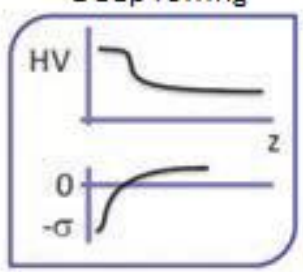

Chemical-mechanical

- chemical-abrasive polishing

Fig. 7. Comparison of different processes leading to similar surface layer characteristics [12]

Regardless of quite different effects of internal loads on the material during the process, similar effects of modification of the material state were obtained as a result of changes in hardness and residual stress distribution in the subsurface layer.

Figs. $8 a-c$ give examples of component process signature (CPS) for various types of external load. In the case of deep rolling (also grind strengthening from fig. 7) with a dominant mechanical load (fig. 8a), this is the maximum value of flow stress according to the von Mises hypothesis $\left(\varepsilon_{\mathrm{pl}, \mathrm{eq}}\right)$. It was found that the value of flow stress practically remains constant when a burnishing tool with different diameter $d_{\mathrm{b}}$ is used [17]. As a result, the maximum value of stress induced in SL in the feed direction $\sigma_{22}$ (i.e. a measure of material modification) can be easily determined on the basis of a linear correlation with the maximum stress (i.e. internal load of the material).

In turn, for grinding with a dominant continuous thermal load (fig. 8b), the internal thermal load is defined by the maximum temperature gradient $(\max (\Delta \vartheta)$ ), which is closely related to the intensity of austenitic transformation and the generation of residual stress in SL. As can be seen, the minimum stress value corresponds to a temperature gradient of approximately $250 \mathrm{~K} / \mathrm{mm}$ [17].

Producing of a white layer in hard cutting (fig. $8 c$ ) is an example of mechanical-thermal interaction, in which CPS represents stored mechanical energy $\left(e_{\mathrm{me}}\right)$, with its maximum value indicating the occurrence of dynamic recrystallization effect. In this way, the relationships between stored energy $\left(e_{\mathrm{me}}\right)$ and maximum thermal energy $\left(\max \left(e_{\mathrm{th}}\right)\right)$, which is proportional to the maximum temperature in the material volume, determine the 
fields for different values of internal stress. It should be added that dynamic recrystallization is also affected by the value and strain rate of deformation [3], which should be taken into account in further analysis.

a)

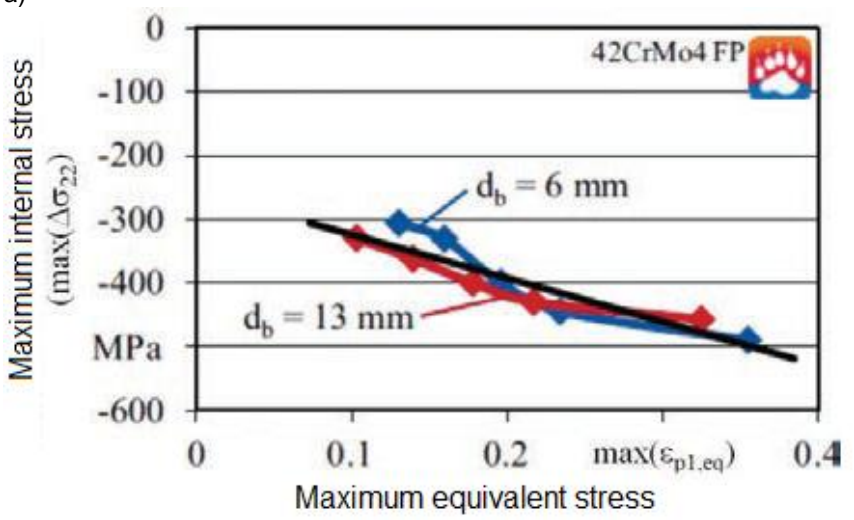

b)

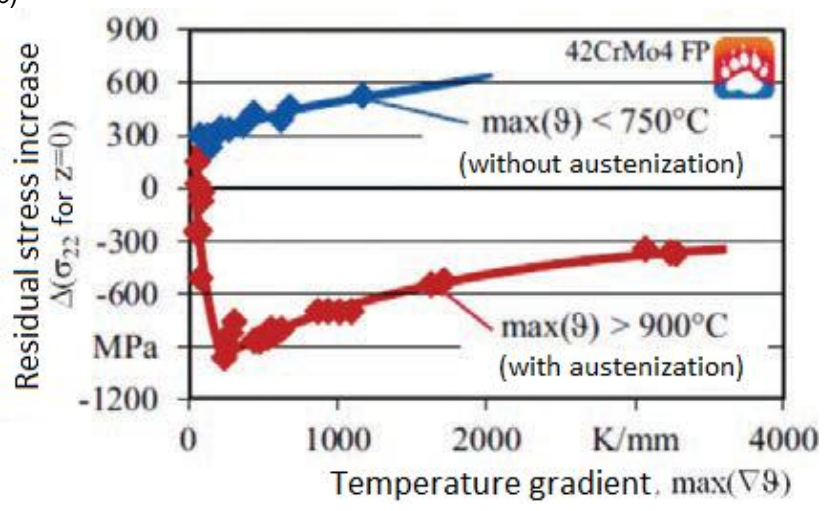

d)

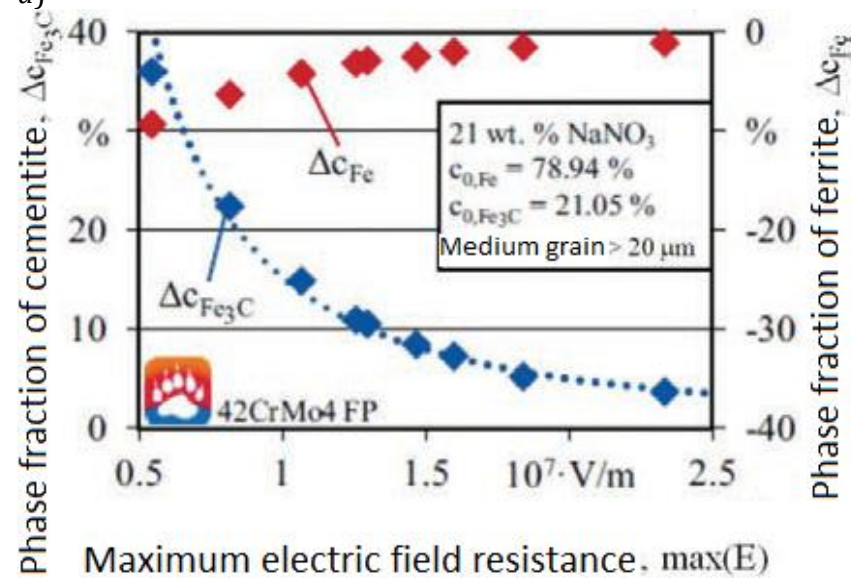

Fig. 8. Examples of CPS for a dominant external load: $a$ ) mechanical - in deep rolling, b) continuous heat - in grinding, $c$ ) mechanical-thermal - in hard turning, d) thermo-chemical - in ECM [15-17]

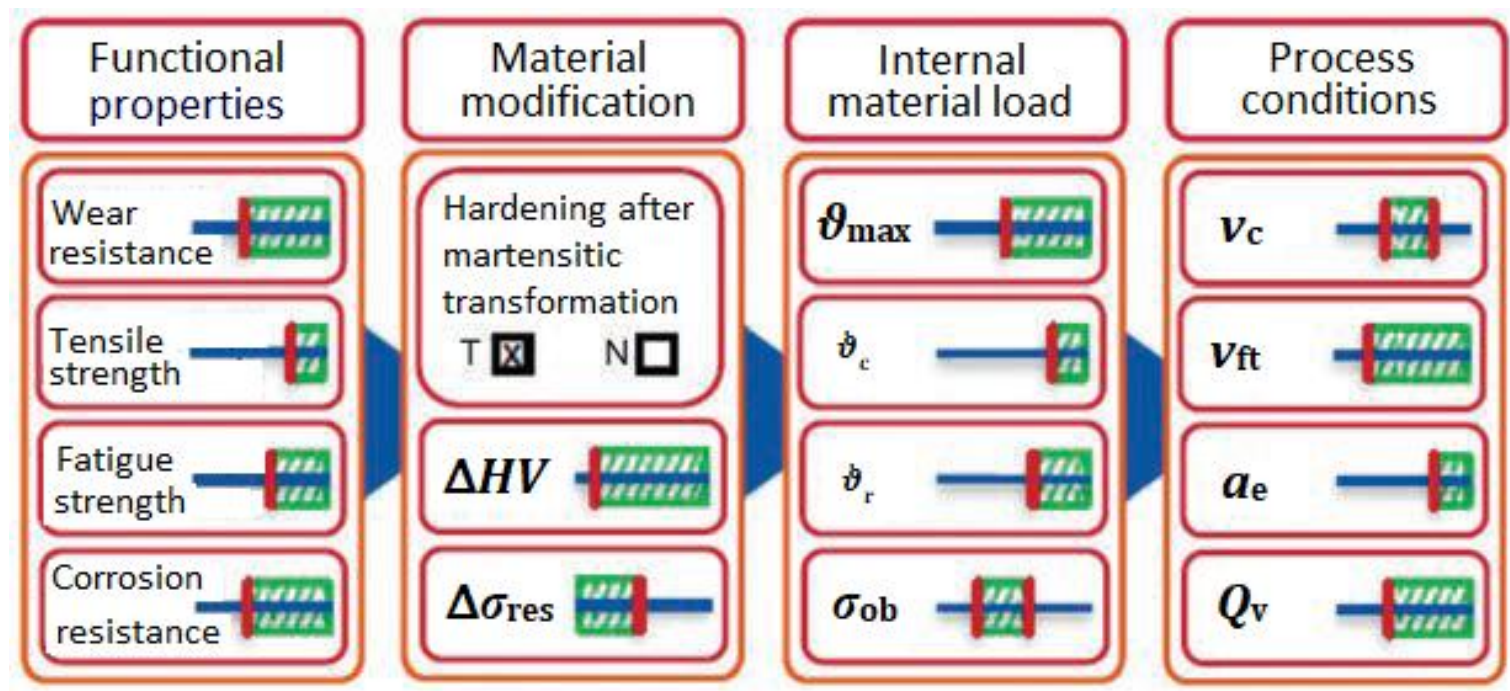

Fig. 9. Application of the PS concept for functionally oriented cutting [13]. Designations:

- material modifications: $\Delta H V$ - change in hardness, $\Delta \sigma_{\text {res }}$ - change in residual stress;

- internal loads: $\boldsymbol{\vartheta}$ - temperature, $\dot{\boldsymbol{\vartheta}}_{\mathrm{c}}$ - temperature gradient causing phase transformation, $\dot{\boldsymbol{\vartheta}}_{\mathrm{r}}-$ temperature gradient causing recrystallization, $\sigma_{\mathrm{ob}}$ - stress in the material caused by external load; - cutting data: $v_{\mathrm{c}}$ - cutting speed, $v_{\mathrm{ft}}$ - tangential feedrate, $a_{\mathrm{e}}$ - radial cutting depth, $Q_{\mathrm{v}}$ - grinding efficiency 
An example of defining the CPS for a process of predominantly thermo-chemical nature (ECM) is illustrated in fig. $8 d$. In this case, the maximum electric field resistance was assumed as internal load, which determines the changes in the proportion of cementite and ferrite phases in the subsurface layer. The reason is different tendency of the metal phases to their dissolution. Increasing the accuracy of modelling of processes with a dominant chemical and thermo-chemical load can be achieved by taking into account the energy of the process, i.e. chemical potential, which determines changes in Helmholtz or Gibbs free energy relative to molar concentration [18].

Fig. 9 summarizes the results of research to date on the application of the CPS concept to two processes: cryogenic burnishing and grinding with one dominant effect on the material. Based on the inverse solution (fig. $5 b$ ), parameters of the machining process were selected in relation to the desired functional properties. By moving the slider, one can adjust the process windows (lined areas in green) and the minimum and maximum limits of a given load (highlighted by red vertical line).

\section{Summary}

The paper discusses the state of knowledge in the field of predicting functional properties of machine parts including resistance to fatigue, resistance to abrasive wear, corrosion resistance - after various machining processes, based on the determination of their functional relationships with the so-called component process signature (CPS). This concept is based on the determination of external and internal loads, and the resulting modification of material properties, which clearly defines the functional properties of the surface of machine parts. The possibilities of predicting functional properties with one dominant (mechanical, thermal or chemical) and complex (thermo-mechanical, thermo-chemical, chemical-mechanical and mechanical-thermochemical) internal load of the material were analyzed. Examples of defining the PS components for grinding, hard machining, cryogenic deep burnishing and ECM are given.

Research institutions face major challenges in that research results must enable the production of parts with required technological and functional properties. According to the author, this is a signal for research teams in this country to take up this subject.

So far, similar studies have been conducted in Germany as part of the DFG research project "Process Signatures" by the universities of Bremen and Aachen under the leadership of prof. E. Brinksmeier - the originator of this concept in 2011. This research corresponds well with the general idea of the Production 4.0 strategy.

\section{REFERENCES}

[1] Grzesik W. „Wpływ topografii powierzchni na właściwości eksploatacyjne części maszyn”. Mechanik. 8-9 (2015): 587-593, https://doi.org/10.17814/mechanik.2015.8-9.493.

[2] Grzesik W. „Hybrydowe procesy obróbki ubytkowej. Definicje, zasady tworzenia i znaczenie w przemyśle”. Mechanik. 5-6 (2018): 338-342, https://doi.org/10.17814/mechanik.2018.5-6.50.

[3] Grzesik W. „Podstawy skrawania materiałów konstrukcyjnych”. Warszawa: PWN, 2018.

[4] Kaczmarek J. „Podstawy obróbki wiórowej, ściernej i erozyjnej”. Warszawa: WNT, 1971.

[5] Field M., Kahles J.F. "Review of surface integrity of machine components”. Annals CIRP. 20, 1 (1971): 107-108.

[6] Jawahir I.S., Brinksmeier E., M'Saoubi R., Aspinwall D.K., Outeiro J.C., Meyer D., Umbrello D., Jayal D. "Surface integrity in material removal processes: recent advances". CIRP Annals. Manufacturing Technology. 60, 2 (2011): 603-626, https://doi.org/10.1016/i.cirp.2011.05.002.

[7] M'Saoubi R., Chandrasakaran H., Outeiro J.C., Dillon O.W., Jawahir I.S. "A review of surface integrity in machining and its impact on functional performance and life of machined products". International Journal of Sustainable Manufacturing. 1, 1-2 (2008): 203-236, https://doi.org/10.1504/IJSM.2008.019234.

[8] Feld M. „Technologia budowy maszyn”. Warszawa: WNT, 1993.

[9] Burakowski T. „Areologia. Podstawy teoretyczne”. Radom: Wydawnictwo Naukowe Instytutu Technologii Eksploatacji, 2013.

[10] Wang B., Shanqiang L. "Influence of tool structure, tool material and tool wear on machined surface integrity during turning and milling of titanium and nickel alloys - a review". Int. J. Advanced Manufacturing Technology. 98, 5-8 (2018): 1925-1975, https://doi.org/10.1007/s00170-018-2314-1.

[11] Willert M., Riemer 0., Brinksmeier E. "Surface integrity in precision turning of steel". Int. J. Advanced Manufacturing Technology. 94, 1-4 (2018): 763-771, https://doi.org/10.1007/s00170-017-0696-0. 
[12] Brinksmeier E., Gläbe R., Klocke F., Lucca D.A. "Process signatures - an alternative approach to predicting functional workpiece properties". Procedia Engineering. 19 (2011): 44-52, https://doi.org/10.1016/i.proeng.2011.11.078.

[13] Brinksmeier E., Klocke F., Lucca D.A., Sölter J., Meyer D. "Process signatures - a new approach to solve the inverse surface integrity problem in machining processes". Procedia CIRP. 13 (2014): 429-434, https://doi.org/10.1016/j.procir.2014.04.073.

[14] Brinksmeier E., Meyer D., Heinzel C., Lübben T., Sölter J., Langenhorst L., Frerichs F., Kämmler J., Kohls E., Kuschel S. "Process signatures - the missing link to predict surface integrity problem in machining". Procedia CIRP. 71 (2018): 3-10, https://doi.org/10.1016/j.procir.2018.05.006.

[15] Brinksmeier E., Reese S., Klink A., Langenhorst L., Lübben T., Meinke M., Meyer D., Sölter J. "Underlying mechanisms for developing process signatures in manufacturing". Nanomanufacturing and Metrology. 1 (2018): 193-208, https://doi.org/10.1007/s41871-018-0021-z.

[16] Frerichs F., Sölter J., Lübben T., Brinksmeier E., Zoch H.-W. "A simulation based development of Process Signatures for manufacturing processes with thermal loads”. Procedia CIRP. 45 (2016): 327-330, https://doi.org/10.1016/j.procir.2016.03.039.

[17] Meyer D., Kämmler J. "Surface integrity of AISI 4140 after deep rolling with varied external and internal loads". Procedia CIRP. 45 (2016): 363-366, https://doi.org/10.1016/j.procir.2016.02.356.

[18] Przybyłowicz K. „Podstawy teoretyczne metaloznawstwa”. Warszawa: WNT, 1999.

[19] Szargut J. „Modelowanie numeryczne pól temperatury”. Warszawa: WNT, 1992. 